\title{
An observational study of a shallow gravity current triggered by katabatic flow
}

\author{
A. Adachi ${ }^{1,2}$, W. L. Clark ${ }^{2,3}$, L. M. Hartten ${ }^{3,2}$, K. S. Gage ${ }^{2}$, and T. Kobayashi ${ }^{1}$ \\ ${ }^{1}$ Meteorological Research Institute, Nagamine 1-1, Tsukuba, Japan \\ ${ }^{2}$ NOAA Aeronomy Laboratory, 325 Broadway, Boulder, Colorado, USA \\ ${ }^{3}$ Cooperative Institute for Research in Environmental Sciences, University of Colorado, Boulder, Colorado, USA
}

Received: 25 November 2003 - Revised: 14 April 2004 - Accepted: 20 April 2004 - Published: 29 November 2004

Part of Special Issue "10th International Workshop on Technical and Scientific Aspects of MST Radar (MST10)"

\begin{abstract}
Observations from a wind profiler and a meteorological tower are utilized to study the evolution of a gravity current that passed over the Meteorological Research Institute's (MRI) field site in Tsukuba, Japan. The gravity current was created by katabatic flow originating on the mountainous slopes west of the field site. The passage of the shallow current was marked by a pronounced pressure disturbance and was accompanied by vertical circulations seen in the tower and profiler data. Direct vertical-beam measurements are difficult, especially at low heights during highgradient events like density currents. In this study vertical velocities from the profiler are derived from the four oblique beams by use of the Minimizing the Variance of the Differences (MVD) method. The vertical velocities derived from the MVD method agree well with in situ vertical velocities measured by a sonic anemometer on the tower.

The gravity current is analyzed with surface observations, the wind profiler/RASS and tower-mounted instruments. Observations from the profiler/RASS and the tower-mounted instruments illustrate the structure of the gravity current in both wind and temperature fields. The profiler data reveal that there were three regions of waves in the vertical velocity field: lee-type waves, a solitary wave and Kelvin-Helmholtz waves. The lee-type waves in the head region of the gravity current seem to have been generated by the gravity current acting as an obstacle to prefrontal flow. The solitary wave was formed from the elevated head of the gravity current that separated from the feeder flow. Profiler vertical-motion observations resolve this wave and enable us to classify it as a Benjamin-Davis-Ono (BDO) type solitary wave. The ducting mechanism that enabled the solitary wave to propagate is also revealed from the wind profiler/RASS measurements. The combination of high-resolution instruments at the MRI site allow us to develop a uniquely detailed picture of a shallow gravity current structure.
\end{abstract}

Correspondence to: K. S. Gage

(kenneth.s.gage@noaa.gov)
Key words. Meteorology and atmospheric dynamics (mesoscale meteorology; waves and tides; instruments and techniques)

\section{Introduction}

Gravity currents, in which flow (usually horizontal) is created due to differences in the density of two adjacent fluids, are important mesoscale phenomena that influence local weather. On relatively flat plains adjacent to mountain slopes, gravity currents may be initiated by katabatic flow, "local downslope gravity flows caused by nocturnal radiative cooling near the surface under calm, clear-sky conditions" (Barry, 1992), coming off the mountains at night. Simpson (1997) and Rottman and Linden (2001) give reviews of theoretical and observational research on gravity currents. In recent years, much progress has been made in the observation and understanding of atmospheric internal solitary waves generated from the gravity currents. Internal atmospheric solitary waves fall into two categories (Rottman and Einaudi, 1993; Rottman and Grimshaw, 2001). The first category is confined to the lower troposphere and is generated locally, while the second category fills the troposphere and is generated by large-scale processes such as geostrophic adjustment. Theoretical aspects of solitary waves in stratified fluids have been reviewed recently by Grimshaw (2001). Application of the theory of solitary waves to the atmosphere is reviewed by Rottman and Grimshaw (2001). In the lower atmosphere for the first class of internal solitary waves, models that use rigid upper boundaries are consistent with the KdV (Kortweg-de Vries) theory, whereas models that use infinite neutrally stratified fluid as an upper boundary are consistent with the BDO (Benjamin-Davis-Ono) theory. On 30 December 1997 a shallow gravity current system passed through the Automated Meteorological Data Acquisition System (AMeDAS) mesoscale network on the Kanto 


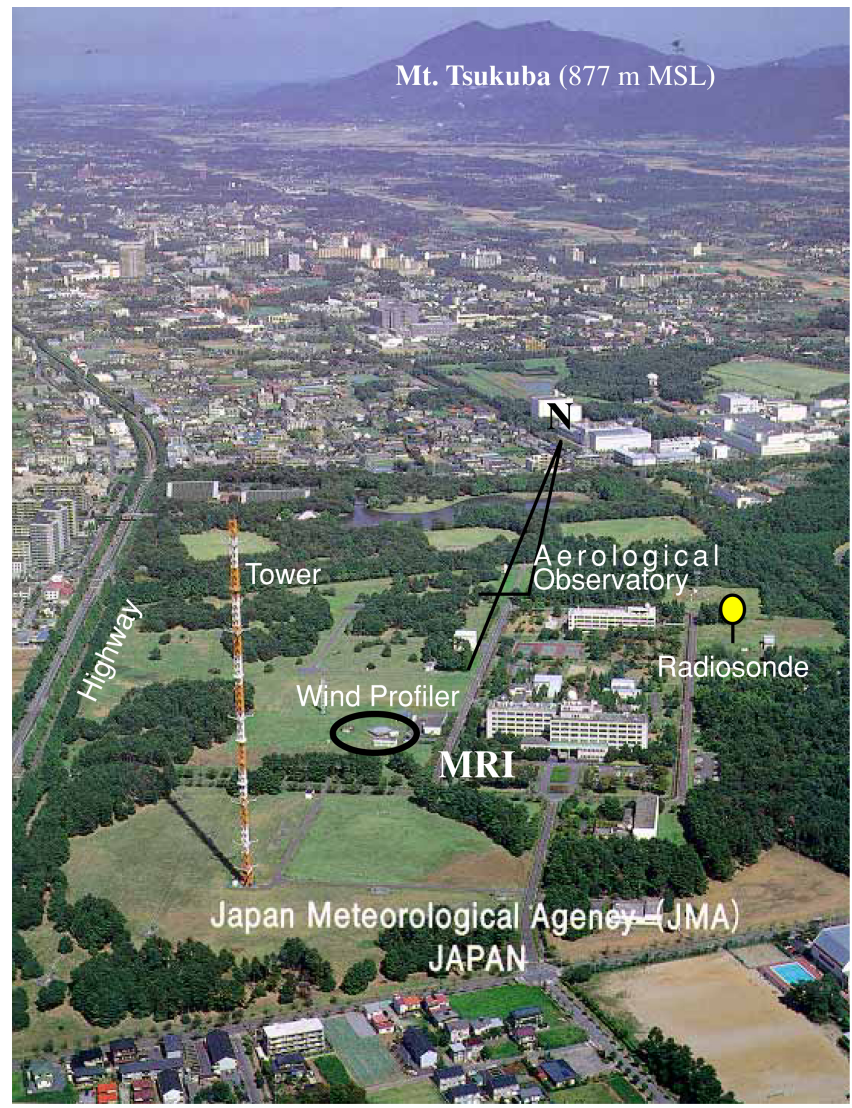

Fig. 1. Picture of the Meteorological Research Institute (MRI) and Aerological Observatory, looking north-northwest towards Mt. Tsukuba. The 213-m meteorological tower has instrument platforms at 10, 25, 50, 100, 150, and $200 \mathrm{~m}$, with additional instruments at the top. A portion of a nearby highway can be seen on the left edge of the photo.

plain in Japan. The gravity current surface front arrived over the Meteorological Research Institute (MRI) instrument array (located on the site of the Japan Meteorological Agency on the outskirts of Tsukuba, Japan) at about 01:00 JST (Japan Standard Time: JST $=\mathrm{UTC}+9 \mathrm{~h}$ ). The vertical structure of this shallow and rather weak system was captured by the 213$\mathrm{m}$ meteorological tower and the nearby collocated $1.3-\mathrm{GHz}$ wind profiler radar/RASS system. In this paper we analyze this shallow gravity current system and related solitary wave. We determine that the wave most closely fits the BDO theory based on the vertical structure of the wave disturbance and its environment revealed by the MRI instrument array. The analysis of this event clearly demonstrates that only by combining all these instrumental systems is it possible to gain a complete picture of the event.

As the gravity current front passed over the MRI at 01:00 JST on 30 December 1997 (Adachi and Kobayashi 2000), large vertical velocities associated with the gravity current were observed with the sonic anemometers mounted on the MRI tower. A special focus of this paper is the validation of the vertical motion and temperature fields ob- tained above the tower using the profiler/RASS observations. This vertical motion field was especially important for distinguishing the BDO type solitary wave from the KdV type. Observation of vertical motions using the vertical beam of the profiler is known to be difficult in practice (e.g. Angevine, 1997). Indeed, in the analysis of the much stronger and deeper gravity current analyzed by Koch and Clark (1999) the vertical beam velocity data were found to be of little use, so that the vertical motion field presented in that paper relied on the integration of the horizontal divergence field obtained from the two oblique beam observations and knowledge of the propagation speed of the current. Similarly, in the present study the vertical beam vertical motion observations often appear spurious. As an alternative, we have calculated the vertical air motions using the Minimizing the Variance of the Differences (MVD) method from Gossard et al. (1998). Comparison of the vertical motion fields at $200 \mathrm{~m}$ altitude observed by both the tower sonic anemometers and the profiler indicate this method works well.

In Sect. 2 of this paper we describe the instruments that are used in this study. In Sect. 3 we present an overview of the synoptic environment in which the solitary wave was generated. The accuracy of vertical velocity determined from the wind profiler using the MVD is examined in Sect. 4 during the passage of the gravity current on 30 December 1997 by comparing vertical velocities derived using MVD with in situ measurements made with a sonic anemometer mounted on the MRI meteorological tower. In Sects. 5 and 6, we analyze the gravity current and associated solitary wave utilizing the observations from the tower and the wind profiler/RASS, and compare with theory. The ability to classify the solitary wave as $\mathrm{KdV}$ or, in this case, BDO is demonstrated.

\section{Instrumentation and data analysis techniques}

Wind profilers equipped with RASS are one of the best tools for studying a gravity current, because they can observe not only the wind but also the temperature profile. A UHF wind profiler of the type originally developed at the NOAA Aeronomy Laboratory (Ecklund et al., 1988; Carter et al., 1995) is used to provide continuous, high-vertical resolution wind measurements in the first few kilometers of the atmosphere. We then use the wind profiler data to study the evolution of the gravity current passage over the MRI site. In particular, the vertical motions observed with the MVD method described below enhance analysis of the dynamics of the gravity current, especially at its head region. The wind profiler observations, including Radio Acoustic Sounding System (RASS) temperatures, are complemented at the Meteorological Research Institute (MRI) field site by a network of surface instruments and observations from a 213-m meteorological tower.

The meteorological tower at the MRI (Fig. 1) is equipped with sonic anemometers that measure three-dimensional wind velocity at six levels $(10,25,50,100,150$ and $200 \mathrm{~m}$ AGL) at the sampling rate of $10 \mathrm{~Hz}$. Each level has three 
Table 1. Parameters of the wind profiler.

\begin{tabular}{ll}
\hline Frequency & $1.3575 \mathrm{GHz}$ \\
Peak Power & $500 \mathrm{~W}$ \\
Beam Width & $10^{\circ}$ \\
Beam elevation & $90^{\circ}$ and $74.5^{\circ}$ \\
Pulse width & $400 \mathrm{~ns}$ \\
First Range Gate & $150 \mathrm{~m}$ \\
Gate Spacing & $60 \mathrm{~m}$ \\
Inter-Pulse Period & $20 \mu \mathrm{s}$ \\
\hline
\end{tabular}

arms on which instruments are mounted. The instruments mounted on the windward arms are selected automatically to avoid the effect of the tower itself. Propeller-driven anemometers, thermometers and hygrometers are mounted at the top of the tower in addition to at the six levels where the sonic anemometers are mounted. A more detailed description of the tower and its instruments can be found in Hanafusa et al. (1979). These tower data are used to analyze the gravity current event throughout the first $200 \mathrm{~m}$. Above $200 \mathrm{~m}$ the wind profiler/RASS data are used.

The MRI wind profiler (a four-panel Vaisala LAP-3000) is located about $300 \mathrm{~m}$ north of the tower, as shown in Fig. 2. The configuration and operating parameters are summarized in Table 1. The profiler was operated in RASS mode for the first $5 \mathrm{~min}$ of each half hour. For winds, the profiler was operated in low mode as a 5-beam system and in high mode as a 3-beam system. We use only the low-mode data in this study. The beam sequence was $\mathrm{V}_{y}, \mathrm{SW}, \mathrm{SE}, \mathrm{NE}, \mathrm{NW}, \mathrm{V}_{x}, \mathrm{~V}_{y h}$, $\mathrm{SW}_{h}$ and $\mathrm{SE}_{h}$, where $\mathrm{h}$ indicates the high mode and $\mathrm{x}$ and $\mathrm{y}$ denote antenna polarization. The dwell time for each beam was about $27 \mathrm{~s}$. For the low mode, the first range gate was $150 \mathrm{~m}$ and the second was $210 \mathrm{~m}$. We selected the second range gate data for the comparison with the sonic anemometer mounted at $200 \mathrm{~m}$, and used higher data for other portions of the study. Since the MVD method estimates the vertical velocity from oblique beams, the height of the second gate was $202 \mathrm{~m}\left[=210\left(\sin \left(74.5^{\circ}\right)\right)\right]$ for the MVD method. The separation between opposing beams increases with height; at $200 \mathrm{~m}$ it is $111 \mathrm{~m}$ (Fig. 2) and at $1 \mathrm{~km}$ it is $555 \mathrm{~m}$.

Unfortunately, the sonic anemometer windward of the tower at $50 \mathrm{~m}$ in height was damaged. Thus, we interpolated the sonic anemometer data from $25 \mathrm{~m}$ and $100 \mathrm{~m}$ to estimate the vertical component at $50 \mathrm{~m}$ and used the propellerdriven anemometer data at $50 \mathrm{~m}$ for the horizontal components. In the wind profiler measurement at the fourth gate (318 m AGL), strong clutter sometimes contaminated the Doppler spectrum and masked the atmospheric echo even in the oblique beams. This clutter was likely caused by automobiles on a highway at the west of the MRI site (Fig. 1); the distance from the profiler to the road is almost equal to the height of the fourth range gate, and this clutter is well correlated to the traffic light on the road. To overcome this problem, we linearly interpolated data from the oblique range gates above and below the 4th gate.

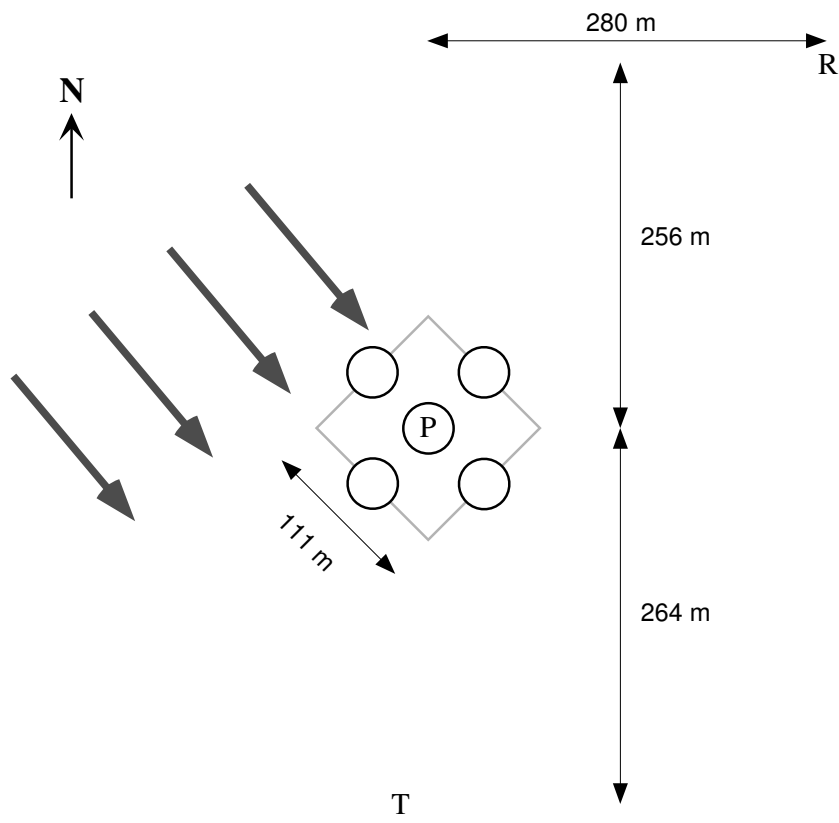

Fig. 2. Schematic layout of the relative locations of the instrumented tower $(\mathrm{T})$, the $1.3-\mathrm{GHz}$ profiler $(\mathrm{P})$, and the radiosonde shed $(\mathrm{R})$ in relation to the gravity current. The footprint of the $10^{\circ}$ vertical profiler beam at $200 \mathrm{~m}$ is shown to scale as a circle around the P; circular approximations of the footprint and location of the oblique beams at $200 \mathrm{~m}$ are indicated by circles to the NE, SE, SW, and NW of the vertical beam and are overlaid on a grey square outline for ease of viewing. Thick grey arrows show the approximate direction $\left(320^{\circ}\right)$ from which the gravity current arrived on 30 December 1997.

One of the unique capabilities of the wind profiler is to be able to rapidly sample the vertical velocity, in addition to the horizontal wind (Gage, 1990; Van Zandt, 2000). This observational capability of wind profilers facilitates understanding the dynamics of mesoscale meteorological phenomena such as cold fronts (e.g. May et al., 1991), mountain waves (e.g. Ralph et al., 1997), gravity waves (e.g. Ralph et al., 1993, Gage and Gossard, 2003), bores (Koch and Clark, 1999) and mesoscale convective systems (Adachi et al., 2004). The accuracy of wind profilers in measuring horizontal components of wind has been estimated by the comparison with radiosondes (e.g. May, 1993), towers (e.g. Angevine et al., 1998), lidar (Cohn and Goodrich, 2002), and in situ measurements (e.g. Angevine and MacPherson, 1995). However, there are few studies on estimating the accuracy of profilers in measuring the vertical velocity, although it has a significant influence on the estimation of horizontal wind, especially during convection (Strauch et al., 1987; Weber et al., 1992). A fundamental problem arises, since in accounting for vertical motion affects on horizontal velocity estimates it is necessary to assume that the vertical velocity is homogeneous over the spatial scale of the separation of the profiler oblique beams. However, the vertical airflow has spatial variability during convection (Gage et al., 1991), which makes it difficult to obtain a representative sample of the vertical motion. The 


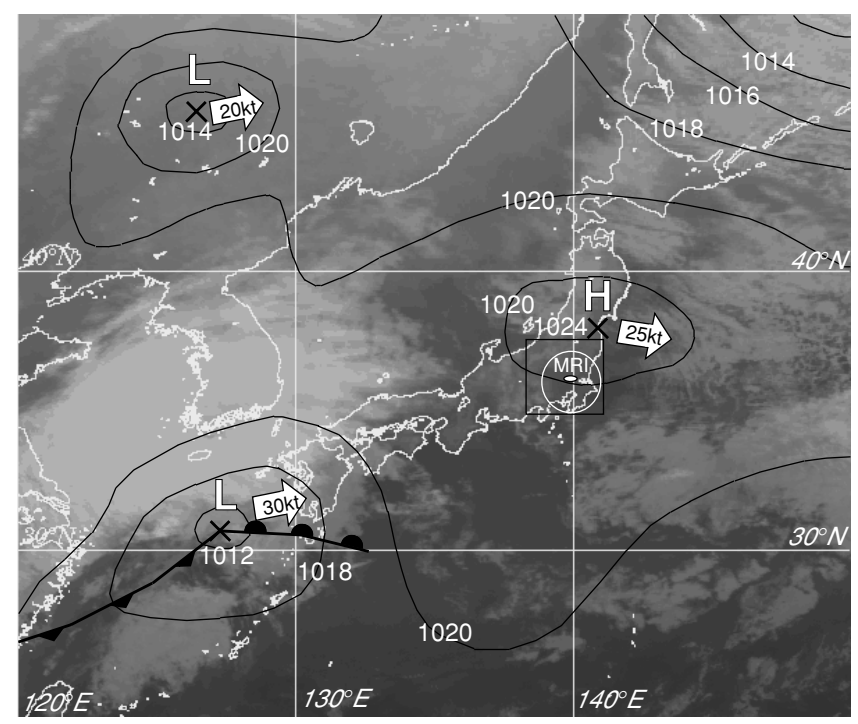

Fig. 3. Surface isobars superimposed over GMS-5 visible imagery from 15:00 JST on 29 December 1997. A square indicates the analytical area in Fig. 5. A white circle surrounds the Kanto Plain, and an oval in the circle indicates the location of the MRI.

magnitude of the vertical airflow in the absence of convection is usually much smaller than that of horizontal airflow and is easily masked by ground clutter (May and Strauch, 1998). The MVD method determines the vertical air motion that minimizes the variance between the four horizontal velocity components calculated from four oblique radial velocities. The radial velocity (positive away from the radar) measured on the north and east antenna beam with the elevation angle $\theta$ at given height is given by

$$
\begin{aligned}
& V_{R N}=v \cos \theta+w \sin \theta \\
& V_{R E}=u \cos \theta+w \sin \theta,
\end{aligned}
$$

where the subscripts $\mathrm{N}$ and $\mathrm{E}$ denote the north and east antenna beams (Strauch et al., 1987). We ignored the radar measurement errors in the equations. The east-component $u$, the north-component $v$, and the vertical velocity $w$ are assumed uniform horizontally across all antenna beams. Horizontal speed components $C_{N E}$ may be computed from Eq. (1) as,

$$
\begin{aligned}
& C_{N E}(w)=\left(u^{2}+v^{2}\right)^{\frac{1}{2}}=\frac{1}{\cos \theta} \\
& \left\{V_{R N}^{2}+V_{R E}^{2}-2\left(V_{R N}+V_{R E}\right) w \sin \theta+2 w^{2} \sin ^{2} \theta\right\}^{\frac{1}{2}},
\end{aligned}
$$

where $C_{N E}$ is a function of $w$ because $V_{R N}$ and $V_{R E}$ are known from oblique beam measurements. It is clear that three other horizontal speed components $\left(C_{E S}, C_{S W}, C_{W N}\right)$ can be derived from other combinations of oblique beams as functions of $w$. The variance of the four speed components, which in theory should be indentical, is given by

$$
\begin{aligned}
& V A R(w)=\left\{\left(C_{\mathrm{ave}}-C_{N E}\right)^{2}+\left(C_{\mathrm{ave}}-C_{E S}\right)^{2}+\right. \\
& \left.\left(C_{\mathrm{ave}}-C_{S W}\right)^{2}+\left(C_{\mathrm{ave}}-C_{W N}\right)^{2}\right\}^{\frac{1}{2}},
\end{aligned}
$$

where $C_{\text {ave }}$ is the average of four speed determinations and is a function of $w$. We used an optimization algorithm (Press et al., 1992) to determine the vertical velocity $w$ that minimizes the variance. Since the MVD method requires the radial velocities of the clear air, this method is not available in rain because in a $1.3 \mathrm{GHz}$ wind profiler the echo from rain masks that from the clear air.

\section{Overview of the gravity current event}

GMS-5 visible imagery (from the Geostationary Meteorological Satellite operated by the Japan Meteorological Agency) at 15:00 JST on 29 December 1997, with superimposed surface isobars (Fig. 3), shows the observation area as well as the larger scale synoptic situation before the onset of the gravity current. A white circle surrounds the Kanto Plain, the region of study, as well as some of the surrounding mountains and ocean. An oval in the white circle indicates the location of MRI. The Kanto Plain, especially west of $140^{\circ} \mathrm{E}$, is relatively cloud-free. Subsequent hourly satellite images (not shown) indicate that this region remained fairly clear until about 19:00 JST, when some cirrus began to overrun the area. There was precipitation associated with the low pressure area to the southwest that reached MRI about 03:00 JST on 30 December, $2 \mathrm{~h}$ after the passage of the gravity current front.

The propagation of the gravity current front was captured clearly with a surface observation network, AMeDAS (Automated Meteorological Data Acquisition System). The evolution of the surface wind vectors and temperature recorded with the AMeDAS are indicated in Figs. 4a-d. The gray scale indicates terrain height with the darkest gray representing more than $2000 \mathrm{~m}$ MSL. The low area located at the southeast part of this figure is the Kanto Plain, which is surrounded by mountains. The ovals represent the locations of AMeDAS stations including MRI.

At sunset (16:00 JST) on 29 December, the predominant flow was easterly at the surface (Fig. 4a). This weak flow under a clear sky was attributable to the high pressure centered just north of MRI (Fig. 3). As the high pressure moved eastward, the easterly flow became weaker with time and some thin cirrus developed. By five hours later (21:00 JST), a cold downslope flow was observed in the mountains west of the Kanto Plain and in the western portion of the Plain itself (Fig. 4b). Note that this flow was not recorded at the stations northwest of the surrounding mountains. This means this flow is not synoptic scale but is a mesoscale phenomenon. Such cold air accelerating downslope at night is often called katabatic flow (Stull, 1988; Barry, 1992).

A front formed between the cold katabatic flow from the mountains and the warmer easterly flow from the ocean. The flow was westerly behind the front, and weak and variable 
but predominantly easterly ahead of the front (Fig. 4c). The front, which marks the leading edge of the gravity current under study, passed MRI about 01:00 JST. The front propagated past MRI at $1.5 \mathrm{~m} \mathrm{~s}^{-1}$, moving toward $140^{\circ}$. These parameters are used in the comparison in Sects. 4-6 to compensate for the distance between the tower and profiler. Along the southern part, the gravity current moved with more northerly flow as it approached the shore because of the local terrain slope. Note that the wind direction recorded on the top of Mt. Tsukuba (877 m MSL, see Figs. 1 and 4a for the location) was southerly during this whole event. This means the depth of the gravity current was shallower than the elevation of this mountain.

The time series of the surface wind vectors and temperature recorded with AMeDAS stations depict the characteristics of the onset and propagation of the gravity current (Figs. 5a-d). The stations are selected so that they are almost on a line parallel to the propagation of the front on the Kanto Plain (Fig. 4a). The wind barbs in Figs. 5a-d are hourly means, and are plotted at the middle of the hourly interval. The temperature values are 10-min means, plotted at the end of the time interval.

The general cooling between 15:00 and 18:00 JST at KSM, KMG and URW is due to radiational cooling after sunset. The cooling could not be due to advection from the east, since the sea surface temperature around the Kanto plain was more than $19^{\circ} \mathrm{C}$ at this time (JMA, 1997). The smaller decrease in temperature at TKO than at other stations during this period may be due to an urban heat island effect (Oke, 1987) and/or proximity to the bay.

The downward pointing triangles in Figs. 5b-d indicate the arrival of the front, which is indicated by a steep decrease in surface temperature associated with a shift in wind direction. In contrast, the shift in wind direction observed at 18:00 JST on 29 December at KSM (Kamisatomi), which is located at the base of the mountains, is not associated with a temperature decrease; rather, the gradient in the temperature trace becomes shallower at this time denoted by the upward pointing triangle. This means a cold air pool created by radiational cooling after sunset (16:00 JST) at KSM is released after the airflow from the ocean became weak. These same features show that the wind shift along with shallower gradient in temperature can be seen at other stations located at the base of the mountains surrounding the Kanto Plain.

The lack of cloud cover over and around the Kanto plain (Fig. 3) is consistent with radiational cooling. This cold air pool is, therefore, the likely source of the gravity current. The reason for the temperature depression at URW (Urawa) near 17:20 JST is unknown. The downward pointing arrows denote the starting time of precipitation from the NE moving low pressure system, which also produces a temperature decrease. Those arrows show that the gravity current front arrived at all the stations well before the precipitation. The Haneda Doppler radar is located just south of Tokyo at Tokyo International Airport (Fig. 4a). Once the precipitation started, the standard weather radar was able to observe the gravity current. Figure 6 shows the radial velocity imagery at (a)

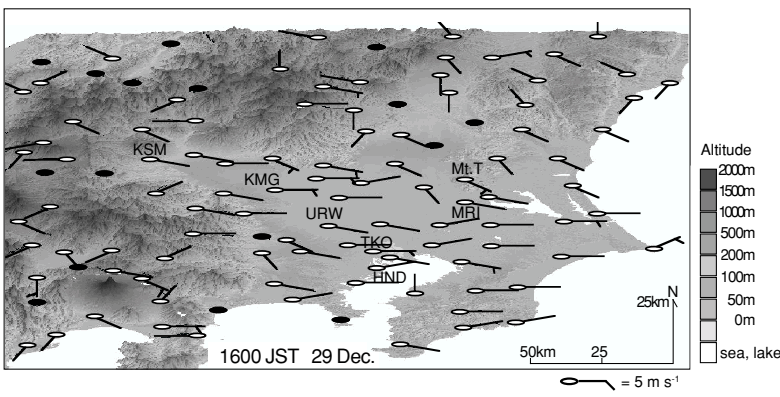

(b)

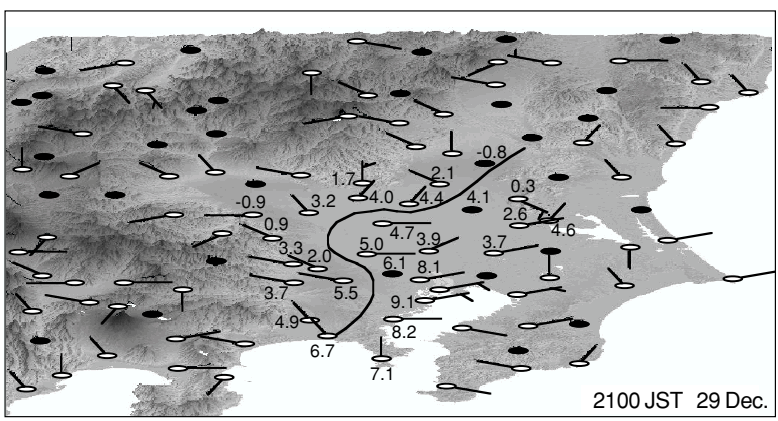

(c)

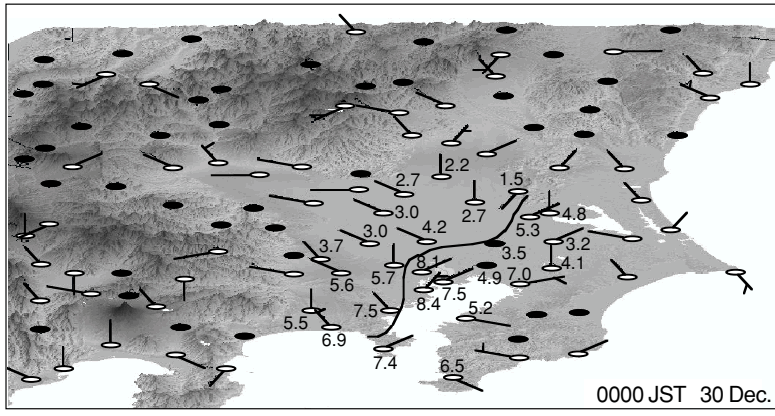

(d)

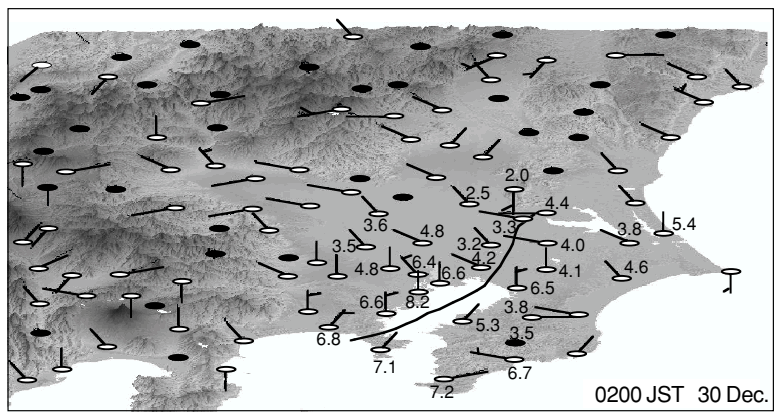

Fig. 4. Surface wind and temperature $\left({ }^{\circ} \mathrm{C}\right)$ observed at (a) 16:00 JST on 29 December, (b) 21:00 JST on 29 December, (c) 00:00 JST on 30 December and (d) 02:00 JST on 30 December. A full wind barb is $5 \mathrm{~m} \mathrm{~s}^{-1}$, and black oval indicates wind speed less than $0.5 \mathrm{~m} \mathrm{~s}^{-1}$. The gray scale represents geographic height. Station names are abbreviated as follows: Kamisatomi, KSM; Kumagaya, KMG; Urawa, URW; Tokyo, TKO; Haneda, HND; and Mt. Tsukuba, Mt.T. Lines in (b) through (d) indicate the location of the gravity current front.

0.7 degrees elevation angle derived from the Haneda Doppler radar at 02:49 JST on 30 December, just after the beginning of rain in the Kanto Plain. An open circle in the center of this 
figure denotes the location of the Haneda radar site. The oval near a lake to the north denotes the location of MRI. The colored area represents the echo from the precipitation. At this time, the precipitation had not reached MRI. The color scale at the side of this figure shows the radial velocity observed with the radar. The positive values represent flow away from the radar. The elevation angle of 0.7 degrees is the lowest possible for this radar because of surrounding buildings. The airflow is southwesterly aloft (denoted with large arrows at southwest and northeast), due to the synoptic situation, and northerly near the surface (denoted with a small arrow over the radar site) in the gravity current. The depth of the gravity current estimated from the height of the $0.0 \mathrm{~m} \mathrm{~s}^{-1}$ contour is about $280 \mathrm{~m}$. This observation was made well into the body of the gravity current event, as precipitation is necessary for the weather radar to observe air motion. The Haneda radar could not observe the gravity current front because there was no precipitation at the time. The wind profiler at MRI could, however, capture the detail of the front.

\section{Comparison of wind profiler/RASS measurements with in situ measurements of tower mounted instru- ments}

As pointed out in the Introduction, there are few, if any, direct comparisons of vertical velocity measurements using profilers with in situ vertical velocity measurements. The only way to accomplish a comparison of this type is to have vertical velocity sensors mounted on a tower. Even with this instrumentation direct comparison is often difficult because the profiler is invariably located some distance from the tower and the vertical motions are usually highly variable in space and time. The 30 December 1997 gravity current provides an opportunity to observe a mesoscale feature with in situ and remote sensors simultaneously. It has a very clear signature in both temperature and winds, and it occurred under synoptic conditions (near midnight in winter while the region was under the influence of a high pressure system) that favor horizontally homogeneous vertical motion. Of course, there are always some issues that arise in direct comparisons of point measurements to measurements which are more representative of a larger volume. This issue should be kept in mind in examining the intercomparisons presented in this section.

Fukuda et al. (1998) and Adachi and Kobayashi (2000) showed that the horizontal components derived from the four oblique beams agree well with the tower measurements. The comparison results presented here go beyond the previous work and show that the wind profiler measurement of the vertical velocity using the MVD method agrees well with the 200-m tower measurement. We begin with the comparison of vertical motions measured by the profiler using the MVD method with the sonic anemometer measurements made on the tower. Then we compare the RASS virtual temperature with the virtual temperature obtained with the towermounted instruments. These results enable a composite anal-

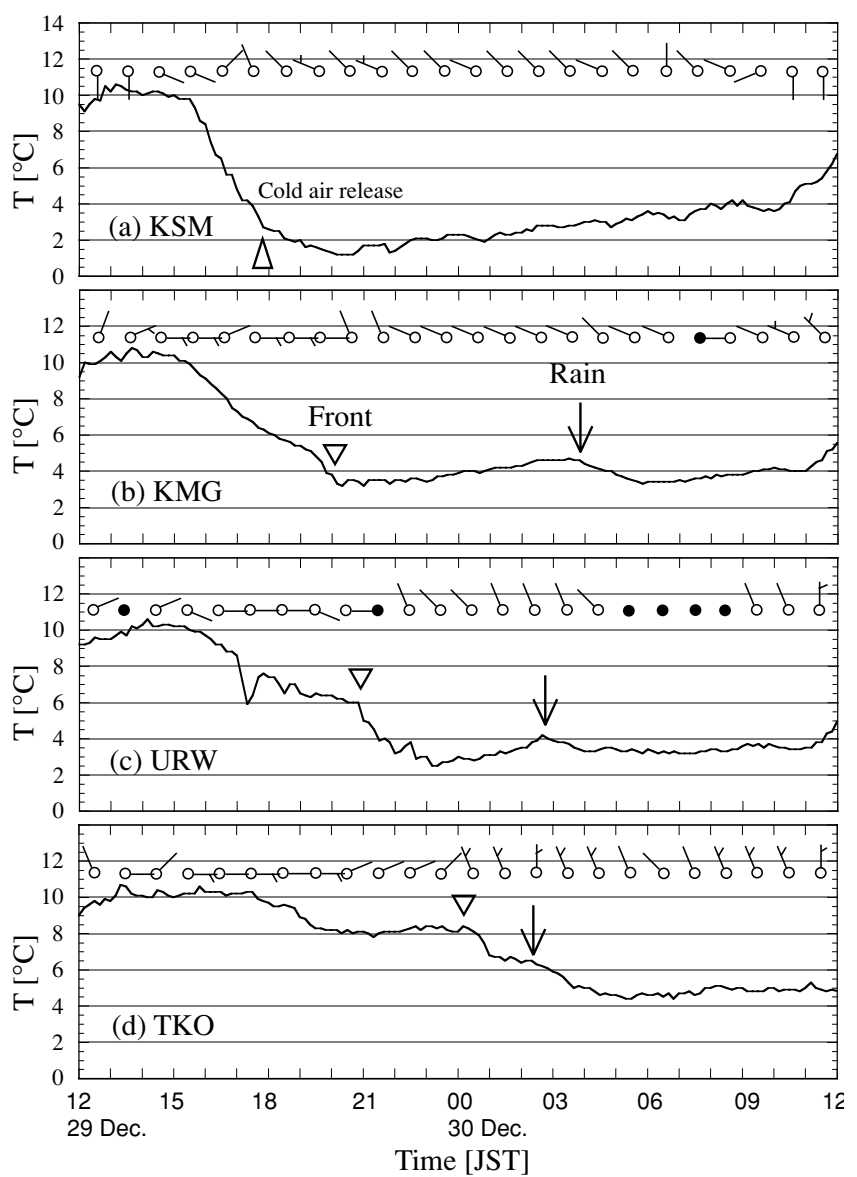

Fig. 5. Time series of the surface wind vectors and temperature recorded at (a) Kamisatomi, (b) Kumagaya, (c) Urawa and (d) Tokyo from 12:00 JST on 29 December to 12:00 JST on 30 December 1997. The upward pointing triangle in (a) indicates the time of the start of the cold air release. The downward pointing triangles in (b)-(d) indicate the arrival time of the front, while the downward pointing arrows show the starting time of precipitation. The wind barbs are hourly means and are plotted at the middle of the hourly interval. The temperature values are 10-minute means, plotted at the end of the time interval.

ysis of three-dimensional airflow from the two instruments, presented in Sect. 5.

Figure 7 shows the time series of the vertical velocity derived from the tower and the wind profiler. The top panel contains the vertical velocity recorded by the sonic anemometer, smoothed with a 2-minute running mean to roughly match the observation duration for the MVD method (about $108 \mathrm{~s}$ ). The lower panel compares the vertical velocity measured by the sonic anemometer $\left(w_{S A}\right)$ with the time series of profiler-measured vertical velocities obtained using the MVD method ( $\left.w_{\mathrm{MVD}}\right)$. The vertical beam was not used, because clutter raised the noise level around $0.0 \mathrm{~m} \mathrm{~s}^{-1}$ in the Doppler velocity spectrum. The times of the profiler measurements have been adjusted by $124 \mathrm{~s}$, which is the time it would take a planar gravity current front moving at $1.5 \mathrm{~m} \mathrm{~s}^{-1}$ from $320^{\circ}$ to travel from the profiler to the tower. The strong 

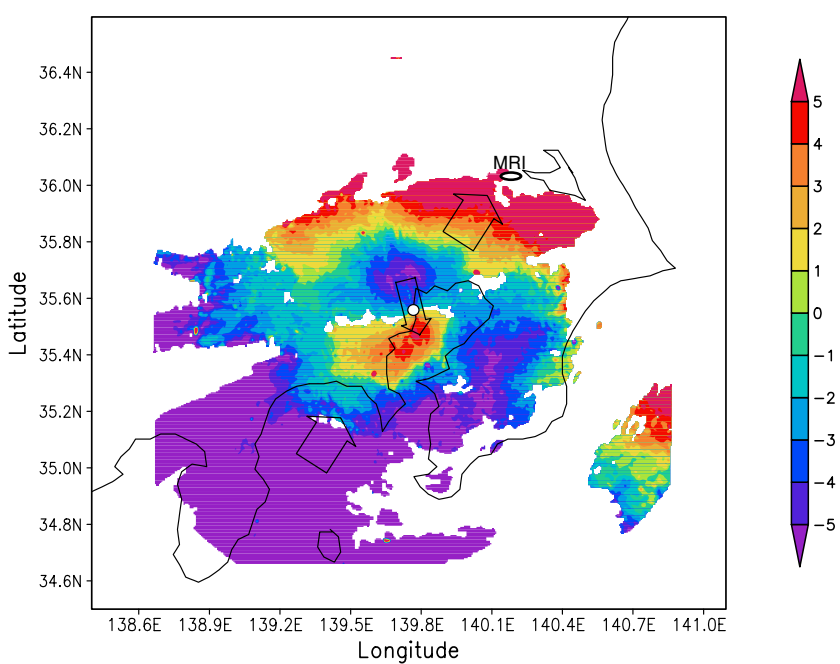

Fig. 6. Radial velocity imagery of the Haneda Doppler radar at $0.7^{\circ}$ elevation angle over the Kanto Plain from 02:49 JST on 30 December 1997. An open circle in the center denotes the location of the radar. An oval near the lake to the north indicates the location of the MRI. The color scale represents radial velocity (positive away from the radar). Large arrows show the wind direction at high altitude, whereas a small arrow indicates the wind direction at low altitude.

upward airflow seen at 01:00 JST in the tower measurement is caused by the passage of the gravity current front. The MVD method captures this upward motion.

One of the essential measurements needed to analyze the dynamics of the gravity current is temperature. The MRI wind profiler is equipped with RASS to provide the profile of virtual temperature $\left(T_{v}\right)$. Figure 8 shows the time series of virtual temperature derived from the tower and the profiler/RASS. The solid line in the middle of the figure represents the virtual temperature derived from thermometers and hygrometers of the tower. The raw data are averaged over five minutes to match the RASS observation. The open circles represent the virtual temperature derived from RASS. In the derivation of the virtual temperature from RASS, we do not correct sound speed with vertical airflow (Angevine et al., 1994), since the signal from the clear air was noisy and was masked by precipitation after 03:00 JST. Nevertheless, the difference between RASS and the tower measurement is smaller than the result of Angevine et al. (1994). This could be due to smaller vertical motions, either because the altitude of our comparison is lower than theirs or because less convection is present due to the synoptic situation. These observations enable a composite analysis of the temperature structure of the gravity current. In the next section, we analyze the horizontal structure of the gravity current to find its characteristics, including the propagation speed of the gravity current front, which is used for the composite analysis in Sect. 6.
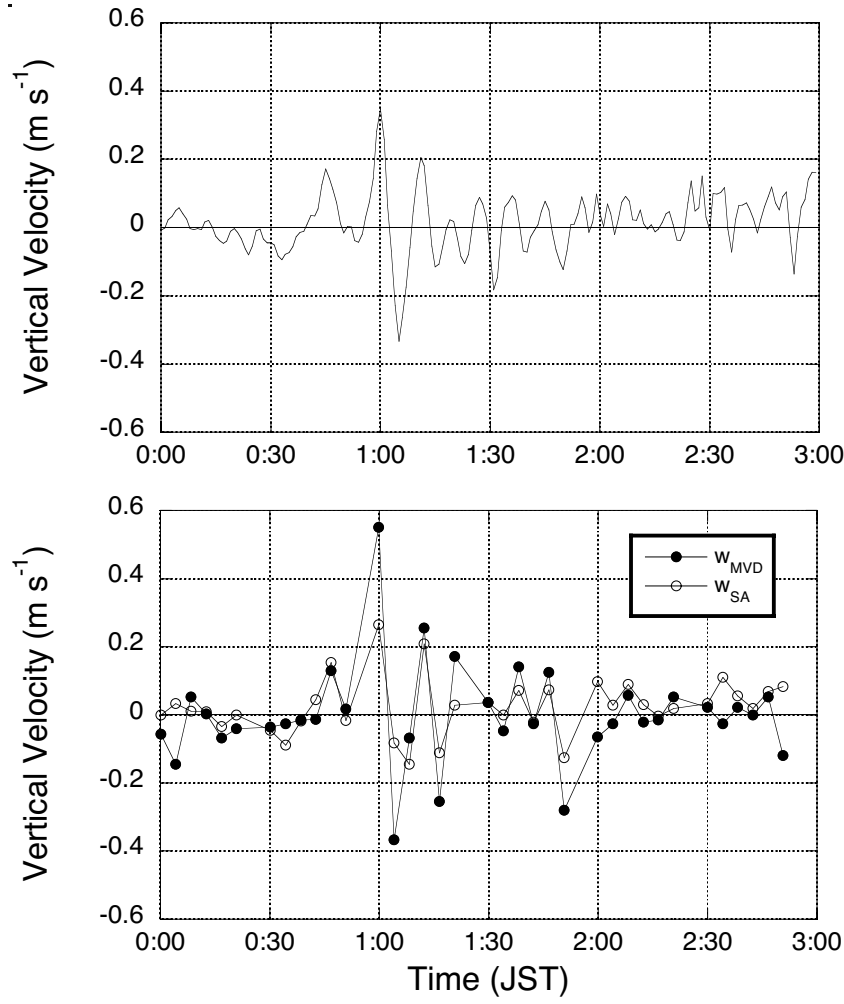

Fig. 7. Time series of vertical air motion derived from the tower and the profiler at 200 $\mathrm{m}$ from 00:00 to 03:00 JST on 30 December 1997. The top panel contains the vertical velocity recorded with the tower-mounted sonic anemometer, smoothed with a 2-minute running mean. The bottom panel contains the vertical velocities obtained from the profiler using the MVD method (closed circles) and from the sonic anemometer (open circles) averaged over the duration for the MVD method. The profiler data have been shifted in time to account for the fact that the gravity current arrived there earlier than at the tower.

\section{Observations of the gravity current}

A time-height cross section of horizontal wind vectors and temperature at MRI appears in Fig. 9. Time increases from right to left, so that the density current appears to move from left to right as it would on a map. In Fig. 9 we are restricting the height of the cross section to $600 \mathrm{~m}$, since the gravity current is confined below about $300 \mathrm{~m}$ and there is no sign of the gravity current in the observations at the top of Mt. Tsukuba. The observations through $200 \mathrm{~m}$ are from the tower. Higher observations are from the wind profiler with RASS. There is no smoothing between the two measurements because they agree well at $200 \mathrm{~m}$, as we mentioned before. The contours with gray scale represent temperature $T$. The humidity profile aloft necessary to convert from $T_{v}$ to $T$ was estimated from a radiosonde launched at 20:30 JST on 29 December from the AO (Aerological Observatory), which is about $380 \mathrm{~m}$ northeast of the wind profiler (Figs. 1 and 2). The humidity profile was linearly interpolated to $100 \%$ at 03:00 JST on 30 December, when precipitation began. The 


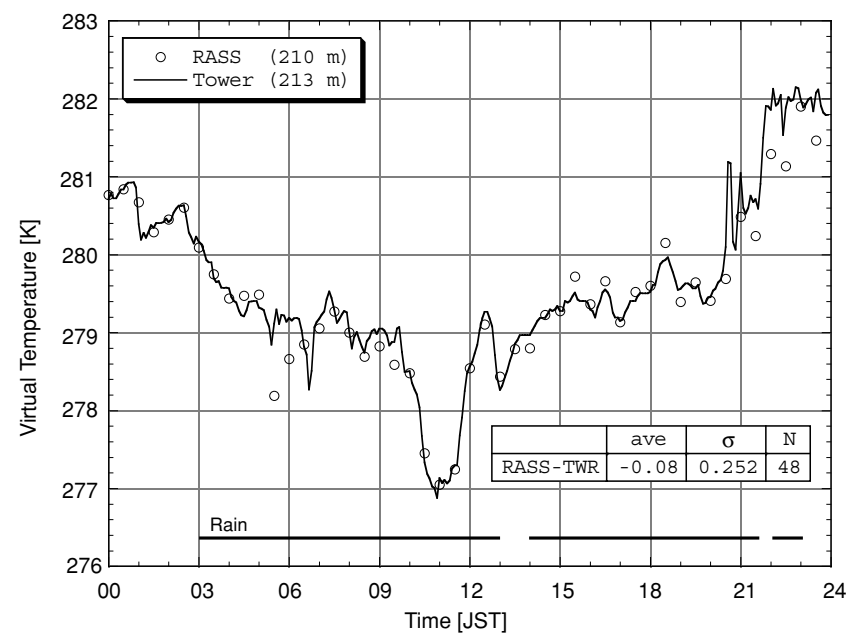

Fig. 8. Time series trace of virtual temperature $\left(T_{v}\right)$ at about $200 \mathrm{~m}$ derived from the tower and RASS from 00:00 to 24:00 JST on 30 December 1997. The solid line represents the tower data, which has been averaged over 5 min to match with RASS measurement. Open circles represent the RASS measurements. Thick lines on the bottom indicate rainy periods. The mean, standard deviation and number of samples of temperature difference are summarized in a table.

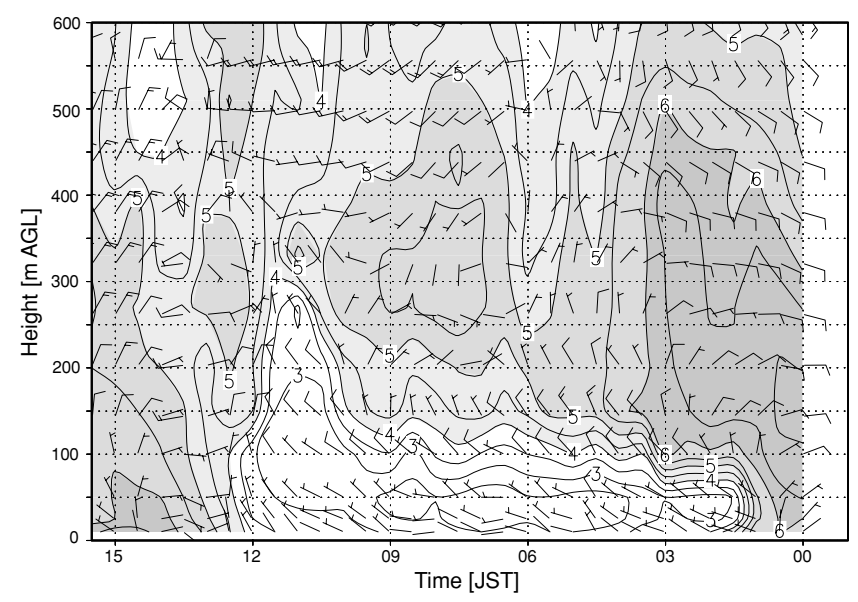

Fig. 9. Time-height cross section of horizontal wind vectors and temperature $\left({ }^{\circ} \mathrm{C}\right)$ from 00:00 to 15:30 JST on 30 December 1997. Time runs from right to left, a full wind barb is $5 \mathrm{~m} \mathrm{~s}^{-1}$, and the contours with gray scale represent temperature with a contour interval of $0.5{ }^{\circ} \mathrm{C}$. The data through $200 \mathrm{~m}$ altitude are from the tower, whereas higher observations are derived from the wind profiler/RASS. The profiler data have been shifted in time so that the gravity current is coincident in the two data sets.

humidity after 03:00 JST is assumed 100\% at all heights. All wind profiler times in this and succeeding figures have been adjusted to account for the fact that the gravity current arrived at the profiler before the tower, as discussed in Sect. 3.

The gravity current is clearly visible along the surface at the bottom of the figure, with its nose indicated by the closely-spaced, vertically-oriented temperature contours at

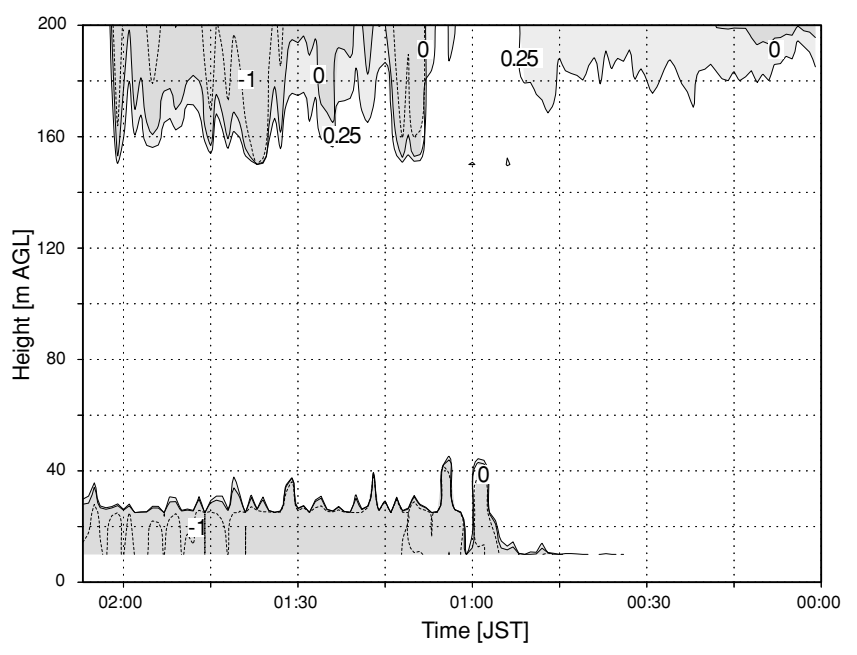

Fig. 10. Time-height cross section of gradient Richardson number (Ri) derived from the tower measurements at 00:00 to 02:05 JST on 30 December 1997. Time runs right to left, and contours with shaded areas represent $R i<0.25$.

the right. Prior to its passage, there were easterly winds and $\mathrm{a} \sim 150 \mathrm{~m}$ deep temperature inversion at the site. After the passage of the gravity current front, the low-level wind direction shifted from northeasterly to northwesterly and the temperature decreased sharply below $100 \mathrm{~m}$. The leveling out of the isotherms atop the current (01:30-03:00 JST) has been noted in other cases of katabatic flow moving into a preexisting temperature inversion (Blumen, 1984; Papadopoulos and Helmis, 1999). The surface temperature at AO decreased $1.7^{\circ} \mathrm{C}$ between 01:00 and 01:30 JST after the passage of the front. The increase of the surface pressure is estimated to be about $0.7 \mathrm{hPa}$ after subtracting the effect of the moving synoptic-scale low pressure system. These facts suggest that the gravity current was cold and heavy, consistent with the generation of a downslope pressure-gradient force and katabatic flow on the mountain slopes. This figure also shows that the depth of the gravity current, estimated from the $5^{\circ}$ isotherm, is about $100 \mathrm{~m}$ at the head. The gravity current, as indicated by the $5^{\circ}$ isotherm, ended at about 12:00 JST. Note that there appears to be no elevated head (Simpson, 1997) on this gravity current. Note also that the inversion layer depth ahead of the gravity current front is about the same as the depth of the gravity current. These facts will be referred to later.

An unstable region is expected along the top of the gravity current due to the strong vertical shear created by the opposing horizontal motions of the current and the adjacent flow aloft. In this situation, Kelvin-Helmholtz (KH) waves are often observed in the shear region if the gradient Richardson number $(R i)$ is less than 0.25 (Miles, 1961). Figure 10 shows the time-height cross section of $R i$ derived from the tower. There are three regions in which $R i$ is less than 0.25: above $170 \mathrm{~m}$ before 01:00 JST, above $150 \mathrm{~m}$ after 01:00 JST, and below $45 \mathrm{~m}$ after 00:30 JST. The first elevated region does 
not have very small $R i$ and is ahead of the gravity current. $\mathrm{KH}$ waves are, therefore, not expected in this region. The region under $40 \mathrm{~m}$ is too close to the surface to develop $\mathrm{KH}$ waves (Davis and Peltier, 1976). The second elevated region is the most promising to produce $\mathrm{KH}$ waves, because $R i$ in this region is small enough and is well above the surface.

The vertical plane wind arrows in Fig. 11 show the twodimensional vector field $(u, w)$, where $u$ is the front-normal horizontal wind and $w$ is the vertical airflow. The vector scale for the vertical motions is amplified by a factor of 10 over the scale of the horizontal motion. The observations through $200 \mathrm{~m}$ altitude are from the tower; higher observations are from the wind profiler, using the MVD method. There is no smoothing between the two observations. The vertical velocity is also indicated by shaded contours, with upward airflow represented by the shading. The gaps seen in between wind profiler observations are caused by the profiler being switched into high mode and RASS configuration. The data derived from the wind profiler are interpolated in time with a cubic spline interpolation to match the time resolution of the tower observations. The temperature measured with the tower is also contoured in the figure to help show the gravity current.

This figure shows that three different phenomena occur. The oscillation seen behind the gravity current head, from $100 \mathrm{~m}$ to $250 \mathrm{~m}$ after 01:20 JST, is a Kelvin-Helmholtz wave, consistent with the layer of low $R i$ shown in Fig. 10. This oscillation produces KH billows within the shear. The extent of this oscillation in height is limited within the shear because KH waves are caused by the shear. The period of this oscillation is $8.4 \mathrm{~min}$, on average. This oscillation becomes obscure after 02:00 JST when the layer of low Ri disappears (Fig. 10).

Ahead of the KH wave, the nose of the gravity current (01:00 JST) contains two cycles of a deep vertical circulation system. The period of this oscillation is $10.6 \mathrm{~min}$, on average, which shows this wave is different from the KH waves mentioned above. This overturning circulation within the gravity current head can be attributed to a forced wave created by mechanical lifting of air at the front. In this mechanism, the front acts as an obstacle and creates a vertical velocity perturbation with much the same form as the displacement perturbation caused by a topographic ridge (Gossard, 1990).

At 00:48 JST, out ahead of the gravity current, there is also a strong upward airflow observed simultaneously by both the sonic anemometer and the wind profiler. It coincides with a peak in the surface pressure (Fig. 12). These observations suggest that this updraft is associated with a solitary wave. One of the characteristics of this updraft is that the maximum $w$ is observed near the top of the layer, implying that this wave was not a KdV (Kortweg-de Vries) but a BDO (Benjamin-Davis-Ono) type of solitary wave. It is necessary that some mechanism that determines the solitary wave height exists. We analyze this mechanism using the profiler/RASS observations in the next section.

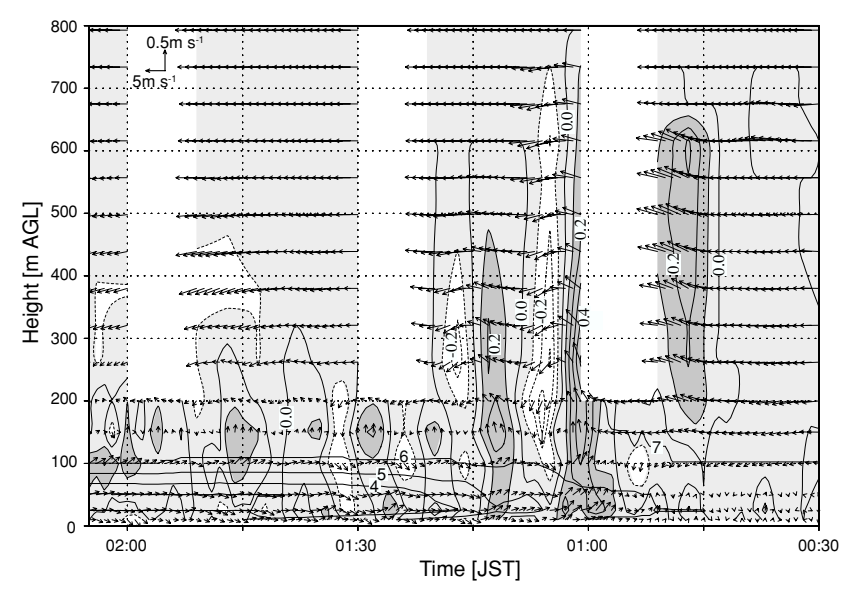

Fig. 11. Two-dimensional flow field derived from the wind profiler and the tower at 00:30 to 02:05 JST on 30 December 1997. Time runs right to left. Horizontal components are the front-normal horizontal wind. Vertical components are magnified by 10 times relative to the horizontal component. The gray scale with contours shows vertical components; upward (downward) airflow is represented with dark shadow (white) regions, respectively. The gaps seen in between wind profiler observations are due to high mode and RASS periods. The temperature measured with the tower is also plotted to represent the gravity current. The profiler data has been shifted in time so that the arrival of the gravity current is coincident in the two data sets.

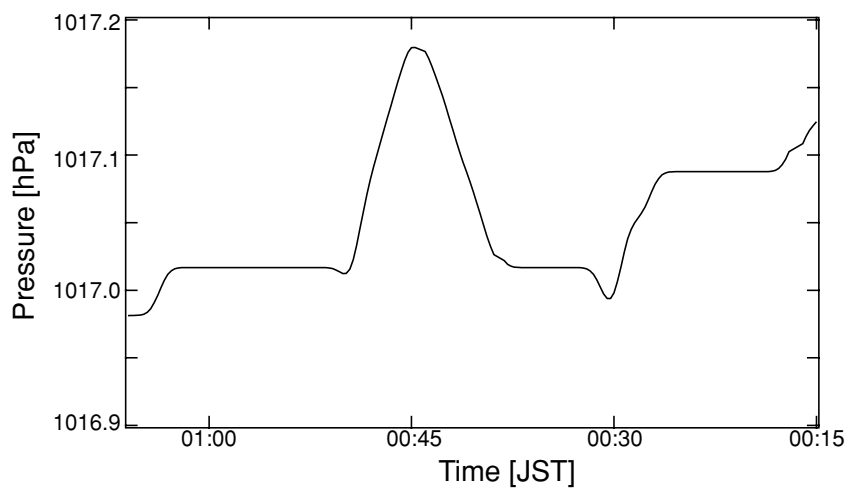

Fig. 12. Time series traces of the surface pressure recorded at the AO from 00:15 to 01:05 JST on 30 December 1997. Time runs right to left.

\section{The solitary wave and its ducting mechanism}

If a gravity current enters a surface-based, low-level stable layer, an internal bore or a closely related solitary wave may form. Such phenomena have often been observed in association with thunderstorm outflow and sea-breeze fronts (e.g. Fulton et al., 1990 and references therein). The conditions for the formation of these nonlinear waves has been studied by Haase and Smith (1989) with a numerical model. They showed theoretically that the gravity current head separates from the feeder flow to form a solitary wave if the depth of the inversion layer ahead is almost equal to, or more than, 


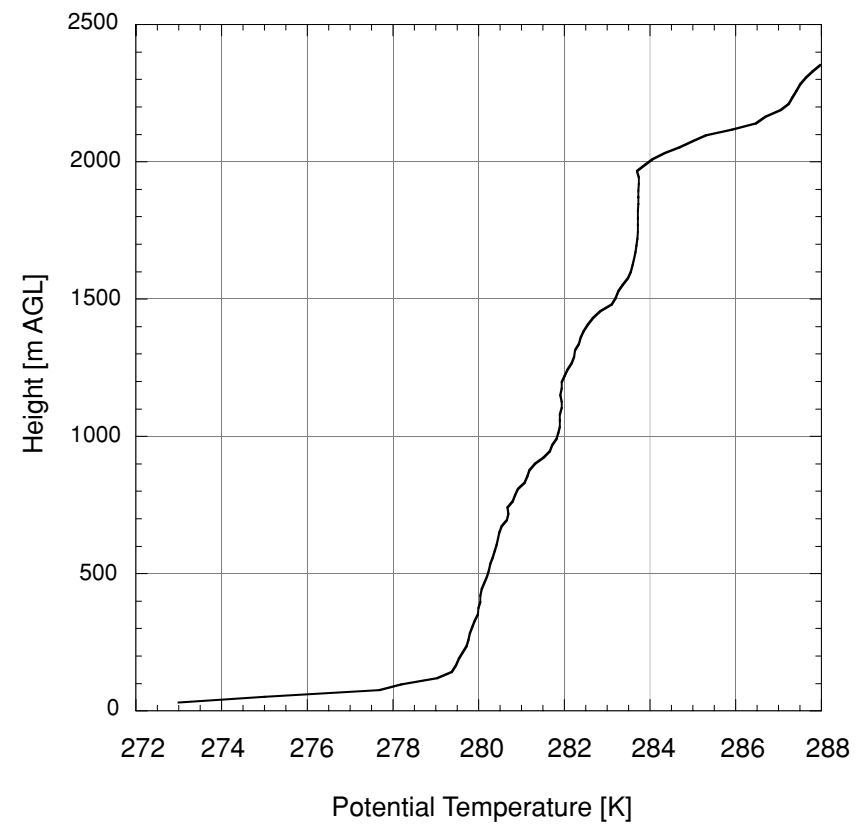

Fig. 13. Profile of potential temperature $(\theta)$ derived from an $A O$ radiosonde observation at 20:30 JST on 29 December 1997.

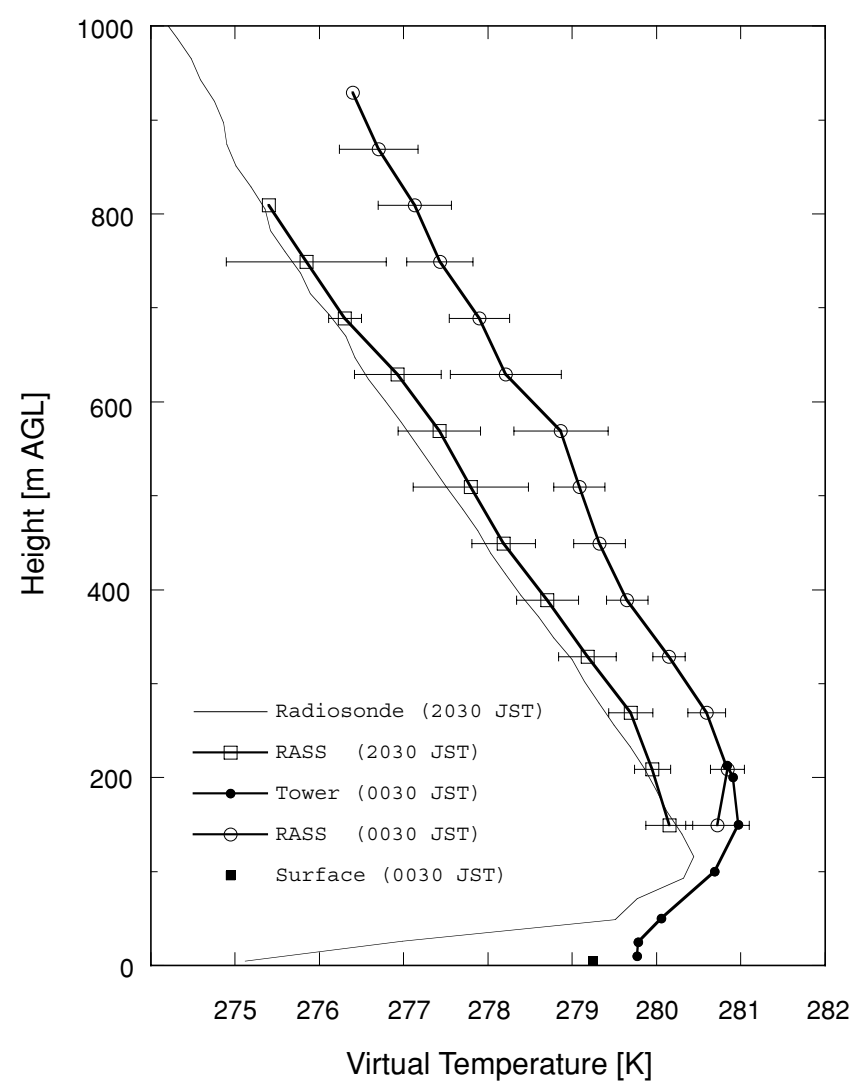

Fig. 14. Profile of virtual temperature $\left(T_{v}\right)$ from 20:30 JST on 29 December and from 00:30 JST on 30 December 1997 derived from the surface measurement, a radiosonde, the tower and RASS. The error bars represent $2 \sigma$ in RASS observation. that of the gravity current. Although they said this is not the usual situation in the atmosphere for sea breezes or thunderstorms, this situation is possible for the katabatic flow in this study; the depth of inversion layer is about $150 \mathrm{~m}$, whereas the depth of the gravity current is about $100 \mathrm{~m}$.

The solitary waves are classified into two types, the $\mathrm{KdV}$ and the BDO. The passage of the solitary wave is associated with a pressure peak or a pressure depression. This type of pressure change cannot determine the type of solitary wave because it does not depend on the type of solitary wave but rather on the depth of the wave duct in which the wave propagates, although the BDO type usually exhibits a pressure peak. The difference between the two types of the solitary waves appears in the profile of vertical velocity (Rottman and Einaudi, 1993). For the BDO type, the largest vertical displacement (an up-down motion) occurs at the top of the waveguide, whereas for the KdV type it occurs in the middle of the waveguide. Our result agrees well with the BDO type because the maximum upward motion is observed at the top of the solitary wave; downward motion after the updraft could not be confirmed due to both RASS and high-mode observation gaps.

The BDO theory is strictly valid only when the upper layer is neutrally stratified. If the upper layer is weakly stratified, then the waves in the lower layer are no longer truly trapped. Figure 13 shows the profile of potential temperature derived from a radiosonde launched from $\mathrm{AO}$ (Fig. 1) at 20:30 JST on 29 December. This figure shows that the atmosphere is nearly neutrally stratified from $150 \mathrm{~m}$ to $2000 \mathrm{~m}$ in altitude. Rottman and Einaudi (1993) indicated that the solitary wave can propagate in a nearly neutrally stratified atmosphere if there is a deep enough region of negative $K^{2}$ (or even small positive values of $K^{2}$, where $K$ is the Scorer parameter) above the wave. They also proposed that a layer of low $N^{2}$, where $N$ is the Brunt-Väisälä frequency, can also act as a reflector of the wave. We, therefore, derive the profiles of $K^{2}$ and $N^{2}$ from profiler and RASS measurements to find these conditions.

Figure 14 shows the profiles of virtual temperature $\left(T_{v}\right)$ at 20:30 JST on 29 December and at 00:30 JST on 30 December, derived from surface, radiosonde, tower and RASS observations. The radiosonde was launched from the AO at 20:30 JST on 29 December, about four hours before the passage of the solitary wave. The $T_{v}$ derived from the radiosonde agrees well with RASS at 20:30 JST, lying within the error bars of RASS measurement. The bias of the RASS may be attributable to the increase of $T_{v}$ with time in the observation. Indeed, the $T_{v}$ at the surface increased $4 \mathrm{~K}$ over four hours. On the other hand, the $T_{v}$ from RASS at 00:30 JST agrees well with the tower measurement at altitudes of $150 \mathrm{~m}$ and $200 \mathrm{~m}$. These results show that the $T_{v}$ profile measured with RASS is reliable. However, this result also suggests that the radiosonde measurement cannot be used for the analysis of the ducting mechanism, because the $T_{v}$ profile changed greatly over the four hours.

The profiles of virtual potential temperature derived from tower and RASS at 00:30 JST on 30 December are plotted 
in Fig. 15a. The surface data recorded at the AO were used as a boundary condition for the derivation of the virtual potential temperature. The actual measurements are plotted as open circles, and the smoothed analytic function fit used in the following calculation is plotted as a solid line. A combination of cubic spline interpolation and linear least-square interpolation is used for the analytic function. This profile shows an inversion layer at about $600 \mathrm{~m}$, which agrees well with the altitude of the top of the solitary wave observed with the wind profiler. Thus, this result is promising for the ducting mechanism.

The Scorer parameter, $K$, is often used as a parameter for a wave duct because waves can be trapped below the region of negative $K^{2}$ (or even small positive $K^{2}$ ). $K$ is given by

$$
\begin{gathered}
K^{2}(z)=\frac{N^{2}}{\left(u_{0}-c\right)^{2}}-\frac{u_{0}^{\prime \prime}}{\left(u_{0}-c\right)}-\frac{1}{2}\left(\frac{\rho_{0}^{\prime}}{\rho_{0}}\right)^{\prime}- \\
\left(\frac{1}{2} \frac{\rho_{o}^{\prime}}{\rho_{o}}\right)^{2}-\frac{u_{0}^{\prime} \rho_{0}^{\prime} / \rho_{0}}{\left(u_{0}-c\right)},
\end{gathered}
$$

where $N$ is the Brunt-Väisälä frequency, $u_{0}$ is the background velocity, $c$ is the phase speed of the wave and $\rho_{\mathrm{w}}$ is the density. In the Boussinesq approximation, since the variation of the background density is negligible, only the first two terms in the equation are kept (Rottman and Einaudi, 1993). For the solution of (4), the Brunt-Väisälä frequency $N$ can be derived from the profile of the virtual potential temperature (Fig. 15a). Hence, the background velocity $u_{0}$ and the phase speed of the solitary wave $c$ should be determined to derive the profile of the Scorer parameter.

The background velocity is the wind component in the direction of propagation of the solitary wave. Since the propagation direction of the solitary wave is not provided from the observation, we assume that the direction is parallel to that of gravity current front, although Cheung and Little (1990) report that the directions of solitary waves are not always parallel to those of the gravity currents behind. The sounding of wind speed in the direction of the propagation of the gravity current front is plotted in Fig. 15b. The actual measurements are plotted as open circles and the smoothed analytic function fit used in the calculation of $K$ is plotted as a solid line. We use the binomial smoothing operation (Marchand and Marmet, 1983), which is a kind of Gaussian filter, for an analytic function because the commonly used smoothed cubic spline method could not fit the observation data well, as pointed out by Rottman and Einaudi (1993).

On the other hand, the phase speed $c$ of a solitary wave necessary to calculate the Scorer parameter is given by $c=2 N H / \pi$, where $N$ is the Brunt-Väisälä frequency and $H$ is the depth of the stable layer. As pointed out by Haase and Smith (1989) and Rottman and Einaudi (1993), if the gravity current front moves faster than the solitary waves on the prefrontal stable layer, a condition referred to as supercriti$\mathrm{cal}$, the resulting undulations will be contained in the postfrontal region. In our case, $c=2.5 \mathrm{~m} \mathrm{~s}^{-1}$ (based on $d \theta_{v} / d z=$ $0.019 \mathrm{~K} / \mathrm{m}$, average $\theta_{v}=279.7 \mathrm{~K}$ and $H=150 \mathrm{~m}$ ) and $C_{\text {front }}=$
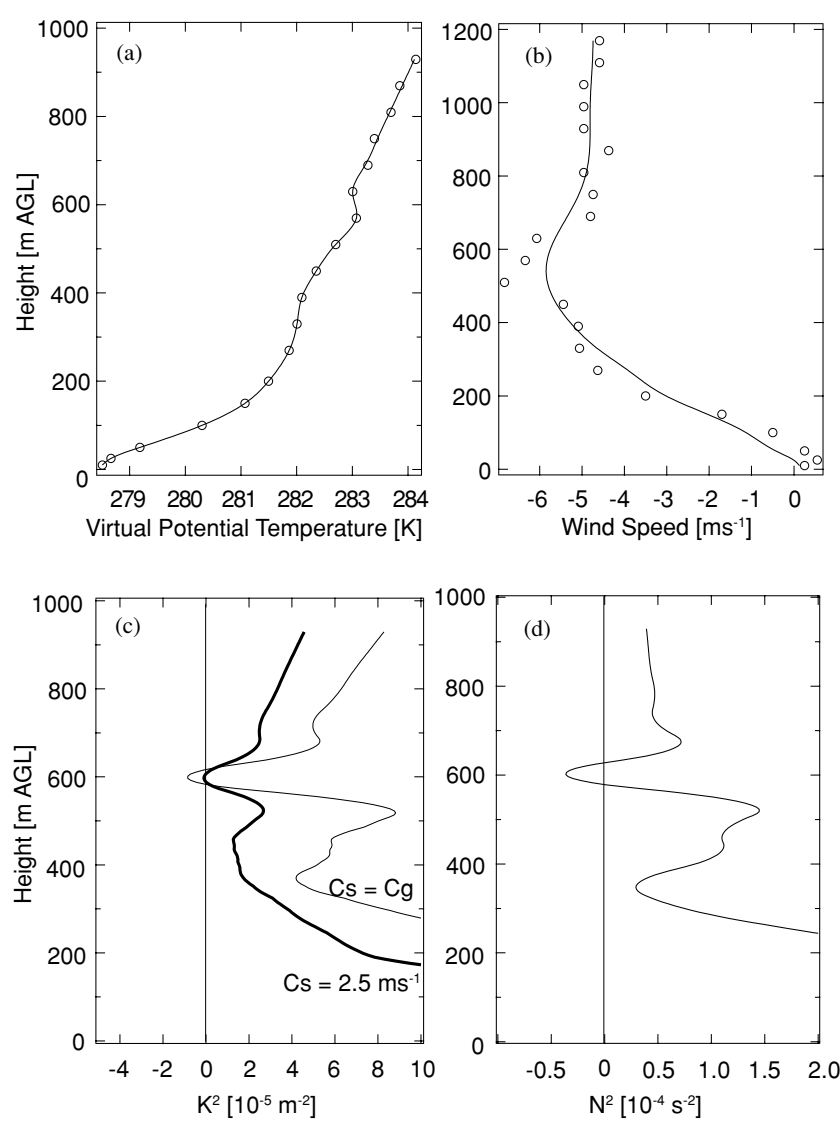

Fig. 15. Vertical structure of the lower troposphere at the MRI site. (a) Profile of virtual potential temperature $\left(\theta_{v}\right)$ derived from tower and RASS at 00:30 JST on 30 December 1997. Open circles indicate actual measurements. A solid line indicates smoothed analytic function fit to the measurements. (b) Profile of wind speeds normal to the gravity current front ( $140^{\circ}$ from north) averaged over 00:0000:30 JST on 30 December 1997. Open circles indicate actual measurements. A solid line indicates smoothed analytic function fit to the measurements. (c) Profiles of the squares of the Scorer parameter $\left(K^{2}\right)$ at 00:30 JST on 30 December 1997. The darker line represents $K^{2}$ for the solitary wave whose phase speed is $2.5 \mathrm{~m} \mathrm{~s}^{-1}$, whereas the lighter line indicates $K^{2}$ for the solitary wave whose phase speed is equal to the propagation speed of the gravity current front. (d) Profile of the square of the Brunt-Väisälä frequency $\left(N^{2}\right)$ at 00:30 JST on 30 December 1997.

$1.5 \mathrm{~m} \mathrm{~s}^{-1}$. Thus, our case is subcritical, and any frontal undulations could propagate ahead of the front, which agrees well with our observation.

Plots of $K^{2}$ and $N^{2}$ computed from the analytic functions are shown in Figs. 15c and d. The profile of $K^{2}$ for the solitary wave, whose propagation speed is equal to that of the front, is also plotted as a reference in Fig. 15c, which shows that a region of low $K^{2}$ exists just above the solitary wave. On the other hand, Fig. 15d shows a region of low $N^{2}$ also exists just above the solitary wave. These facts suggest that there are some layers that trap the solitary wave if the theory of weakly nonlinear waves can be applied to this wave. 
Rottman and Einaudi (1993) show that regions of low $K^{2}$ and $N^{2}$ can act as wave ducts for the BDO solitary wave based on the weakly nonlinear theory. This theory requires the condition that both the ratios of the maximum vertical displacement of the wave to the depth of the waveguide and the ratio of the waveguide depth to the horizontal length scale of the wave are significantly less than one. The displacement derived from the updraft caused by the solitary wave is about $60 \mathrm{~m}$ on average (Fig. 11). The depth of the waveguide is about $600 \mathrm{~m}$ (Figs. 15c and d). The wavelength of the solitary wave estimated from the phase speed $c$ and the period of the pressure peak (about $11 \mathrm{~min}$ in Fig. 12) is about $1700 \mathrm{~m}$. The ratios derived from these variables are 0.1 and 0.35 , respectively. These results suggest that the weakly nonlinear wave theory is applicable to the solitary wave presented.

The combination of the low $K^{2}$ and low $N^{2}$ regions could act as a waveguide to propagate the solitary wave. However, this combination may not be enough to trap all the wave energy because neither are very deep. In this case the solitary wave should not be long-lived but evanescent, although some solitary waves can propagate more than 10 hours (Lin and Goff, 1988). It would appear this solitary wave was generated only $15 \mathrm{~min}$ before passing over the wind profiler (assuming both the propagation speeds of the gravity current front and solitary wave are constant). Nevertheless, we conclude that there are some layers that determine the top of the solitary wave, where the largest amplitude of the vertical motion was observed with the profiler data.

\section{Concluding remarks}

In this paper we have examined a gravity current and associated vertical circulation as it passed over the MRI field site. Data collected by collocated surface instruments, a meteorological tower, and a wind profiler/RASS enable us to gain a better understanding of the structure and dynamics of this wave event. Since we depend on a composite of the tower and wind profiler/RASS measurements to gain a perspective on the vertical structure of the event, we have compared the wind profiler/RASS observations with the highest level of in situ measurements available on the tower. The gravity current passed over the two instruments near midnight on a winter evening when the area was under the influence of a high pressure system, so it was reasonable to assume horizontally homogeneous conditions between the two platforms, which were about $300 \mathrm{~m}$ apart, as well as across the oblique beams of the profiler, which were about $555 \mathrm{~m}$ apart at $1 \mathrm{~km}$ altitude. We derived the vertical velocity from the four oblique profiler beams by use of the MVD method, which was proposed by Gossard et al. (1998). We have demonstrated good agreement between the vertical velocities and virtual temperature from the two platforms.

The MVD results were more reliable than the vertical velocity obtained directly from the vertical beam, which was contaminated by ground clutter. However, the MVD method can be used only in non-precipitating periods when used with data from a $1.3 \mathrm{GHz}$ wind profiler. It also requires horizontal uniformity of the vertical velocity across all the oblique antenna beams. This means that this method may not be valid at very high altitudes above the profiler or under convective conditions, where the region across the beams is larger than the scale of a particular phenomenon. Therefore, the reliable vertical beam observation is still necessary in such high altitude observation and/or under convective conditions. On the other hand, the MVD method is available for use with other remote sensors based on the Doppler Beam Swinging (DBS) method, to improve the accuracy of the vertical component at short range. Sodars that transmit acoustic beams in more than four directions could also use this method to improve measurements. Moreover, this technique could also be available for acoustic Doppler current profilers (Schott et al., 1993), which observe the ocean current with the DBS method (King et al., 2001).

We have analyzed the gravity current with the surface, tower, and profiler observations. The surface observations showed that this gravity current was a katabatic flow. The profiler/RASS and the tower measurements revealed the whole structure of the gravity current in both wind and temperature fields. The profiler data revealed that there were three regions of waves: Kelvin-Helmholtz waves, lee-type waves and a solitary wave. $\mathrm{KH}$ waves occurred within the region of $R i<0.25$ behind the head of the gravity current. The lee-type wave in the head region seems to be generated by the gravity current acting as an obstacle to prefrontal flow. The solitary wave should be formed by the elevated head of the gravity current that separated from the feeder flow due to a stable layer ahead, whose depth was close to that of the gravity current. Christie et al. (1978) suggested katabatic flow draining onto a plain as the source of solitary waves they documented in surface pressure records from central Australia. Our high-resolution vertical motion measurements from the profiler enabled us to identify this solitary wave as the BDO type, supported by the fact that the maximum vertical motion appears at the top of the wave structure. We also find regions of low $K^{2}$ and low $N^{2}$ just above the solitary wave, indicating that each region could act as a waveguide. Although the thicknesses of the two regions are not so deep, we conclude that these regions determine the top of the solitary wave, where the largest amplitude of the vertical motion was observed with the profiler.

In summary, we confirm the fact that the use of an array of instruments is invaluable in the study of mesoscale phenomena. Clearly, the detailed vertical structure in the first $200 \mathrm{~m}$ that are so clearly documented using the tower data would have gone unseen in this shallow event if only profiler data were available. On the other hand, the clear identification of the BDO solitary wave and its ducting mechanism would not have been possible without the profiler/RASS data. It is very encouraging that the MVD method of observing vertical motion appears to be reliable in this case study. Whether this method will remain robust in more extreme events remains to be tested. 
Acknowledgements. The authors would like to express their gratitude to S. E. Koch of the NOAA Forecast Systems Laboratory, Dr. Patrick Haertel of CIRES and T. E. Van Zandt of the NOAA Aeronomy Laboratory for many helpful discussions and comments regarding the research presented. The first author wishes to thank J. W. Rottman of the University of California, San Diego for providing the opportunity to use his program for a fitting function. The first author also wishes to thank S. Fukao of the Research Institute for Sustainable Humanosphere (RISH) in Kyoto University for his valuable comments on the analysis of the solitary wave and G. Zeigler of Vaisala for the comments on the analysis of the gravity current. The authors also thank an anonymous reviewer who made many helpful comments that improved the presentation of this work.

Topical Editor U.-P. Hoppe thanks two referees for their help in evaluating this paper.

\section{References}

Adachi, A. and Kobayashi, T.: Radar wind profiler with RASS observations of gravity current, Ninth International Workshop on Technical and Scientific Aspects of MST Radar combined with COST76 final profiler workshop, 304-306, 2000.

Adachi, A., Kobayashi, T. and Kato, T.: Dual wind profiler observations of a line-shaped convective system in southern Kyushu, Japan, J. Meteor. Soc. Japan, 82, 725-743, 2004.

Angevine, W. M.: Errors in mean vertical velocities measured by boundary layer wind profilers. J. Atmos. Oceanic Technol., 14, 565-569, 1997.

Angevine, W. M., Bakwin, P. S. and Davis, K. J.: Wind profiler and RASS measurements compared with measurements from a 450m-tall tower, J. Atmos. Oceanic Technol., 15, 818-825, 1998.

Angevine, W. M., Ecklund, W. L., Carter, D. A., Gage, K. S., and Moran, K. P.: Improved radio acoustic sounding techniques, J. Atmos. Oceanic Technol., 11, 42-49, 1994.

Angevine, W. M. and MacPherson, J. I.: Comparison of wind profiler and aircraft wind measurements at Chebogue Point, Nova Scotia, J. Atmos. Oceanic Technol., 12, 421-426, 1995.

Barry, R. G.: Mountain Weather and Climate. 2nd Edition, 402 pp., Routledge, New York, 1992.

Blumen, W.: An observational study of instability and turbulence in nighttime drainage winds, Bound.-Layer Meteorol., 28, 245269, 1984.

Carter, D. A., Gage, K. S., Ecklund, W. L., Angevine, W. M., Johnston, P. E., Riddle, A. C., Wilson, J. and Williams, C. R.: Developments in UHF lower tropospheric wind profiling at NOAA's Aeronomy Laboratory, Radio Sci., 30, 977-1001, 1995.

Cheung, T. K. and Little, C. G.: Meteorological tower, microbarograph array, and sodar observations of solitary-like waves in the nocturnal boundary layer, J. Atmos. Sci., 47, 2516-2536, 1990.

Christie, D. R., Muirhead, K. J., and Hales, A. L.: On solitary waves in the atmosphere, J. Atmos. Sci., 35, 805-825, 1978.

Cohn, S. A. and Goodrich, R. K.: Radar wind profiler radial velocity: A comparison with Doppler lidar, J. Appl. Meteor. 41, 1277-1282, 2002.

Davis, P. A. and Peltier, W. R.: Resonant parallel shear instability in the stably stratified planetary boundary layer, J. Atmos. Sci., 33, 1287-1300, 1976.

Ecklund, W. L., Carter, D. A., and Balsley, B. B.: A UHF wind profiler for the boundary layer: Brief description and initial results,
J. Atmos. Oceanic Technol., 5, 432-441, 1988.

Fukuda, M., Adachi, A., and Kobayashi, T.: Measurements of wind and temperature with a radar wind profiler (in Japanese), MRI annual research meeting report, 27-34, 1998.

Fulton, R., Zrnic, D. S., and Doviak, R. J.: Initiation of a solitary wave family in the demise of a nocturnal thunderstorm density current, J. Atmos. Sci., 47, 319-337, 1990.

Gage, K. S.: Radar observations of the free atmosphere: Structure and dynamics, Radar in Meteorology: Battan Memorial and 40th Anniversary Radar Meteorology Conference, D. Atlas, ed., 534565, 1990.

Gage, K. S., McAfee, J. R., Carter, D. A., Ecklund, W. L., Riddle, A. C., Reid, G. C., and Balsley, B. B.: Long-term mean vertical motion over the tropical Pacific: Wind profiling Doppler radar measurements, Science, 254, 1771-1773, 1991.

Gage, K. S. and Gossard, E. E.: Recent developments in observations, modelling and understanding atmospheric turbulence and waves, Chapter 6 in Radar and Atmospheric Science: A collection of Essays in Honor of David Atlas, R.M. Wakimoto and R.C. Srivastava, eds., Meteorological Monographs, 30, No. 10, 139174. 2003.

Gossard, E. E.: Radar research on the atmospheric boundary layer, Radar in Meteorology: Battan Memorial and 40th Anniversary Radar Meteorology Conference, D. Atlas, ed., 477-527, 1990.

Gossard, E. E., Wolfe, D. E., Moran, K. P., Paulus, R. A., Anderson, K. D., and Rogers, L. T.: Measurement of clear-air gradients and turbulence properties with radar wind profilers. J. Atmos. Oceanic Technol., 15, 321-342, 1998.

Grimshaw, R.: Internal solitary waves, Chapter 1 in Environmental Stratified Flows, R. Grimshaw, ed., Kluwer Academic Publishers, Dordrecht, The Netherlands, 1-27, 2001.

Haase, S. P. and Smith, R. K.: The numerical simulation of atmospheric gravity currents. Part II. Environments with stable layers, Geophys. Astrophys. Fluid Dynamics, 46, 35-51, 1989.

Hanafusa, T., Fujitani, T., Banno, N., and Uozu, H.: On the meteorological tower and its observational system at Tsukuba science city, Tech. Reports of the MRI, 3, 50pp, 1979.

Japan Meteorological Agency (JMA) Monthly Ocean Report, 60, 34pp, 1997.

King, B. A., Firing, E., and Joyce, T. M.: Shipboard observations during WOCE, Ocean Circulation and Climate, G. Siedler, J. Church and J. Gould, eds., Academic Press, 99-122, 2001.

Koch, S. E. and Clark, W. L.: A nonclassical cold front observed during COPS-91: Frontal structure and the process of severe storm initiation, J. Atmos. Sci., 56, 2862-2890, 1999.

Lin, Y.-L. and Goff,R. C.: A study of a mesoscale solitary wave in the atmosphere originating near a region of deep convection, J. Atmos. Sci., 45, 194-206, 1988.

Marchand, P. and Marmet, L.: Binomial smoothing filter: A way to avoid some pitfalls of least-squares polynomial smoothing, Rev. Sci. Instrum., 54, 1034-1041, 1983.

May, P. T.: Comparison of wind-profiler and radiosonde measurements in the tropics, J. Atmos. Oceanic Technol., 10, 122-127, 1993.

May, P. T. and Strauch, R. G.: Reducing the effect of ground clutter on wind profiler velocity measurements, J. Atmos. Oceanic Technol., 15, 579-586, 1998.

May, P. T., Yamamoto, M., Fukao, S., Sato, T., Kato, S., and Tsuda, T.: Wind and reflectivity fields around fronts observed with a VHF radar, Radio Sci., 26, 1245-1249, 1991.

Miles, J. W.: On the stability of heterogeneous shear flows, J. Fluid Mech., 10, 496-508, 1961. 
Oke, T. R.: Boundary Layer Climates. 2nd Edition. Routledge, New York, 435 pp, 1987.

Papadopoulos, K. H., and Helmis, C. G.: Evening and morning transition of katabatic flows, Bound.-Layer Meteorol., 92, 195-227, 1999.

Press, W. H., Teukolsky, S. A., Vetterling, W. T., and Flannery, B. P.: Numerical Recipes in Fortran: The art of scientific computing. Second Edition, Cambridge University Press, 963pp, 1992.

Ralph, F. M., Mazaudier, C., Crochet, M., and Venkateswaran, S. V.: Doppler sodar and radar wind-profiler observations of gravitywave activity associated with a gravity current, Mon. Wea. Rev., 121, 444-463, 1993.

Ralph, F. M., Neiman, P. J., Keller, T. L., Levinson, D., and Fedor, L.: Observations, simulations, and analysis of nonstationary trapped lee waves, J. Atmos. Sci., 54, 1308-1333, 1997.

Rottman, J. W. and Einaudi, F.: Solitary waves in the atmosphere, J. Atmos. Sci., 50, 2116-2136, 1993.

Rottman, J. W. and Grimshaw, R.: Atmospheric internal solitary waves, Chapter 3 in Environmental Stratified Flows, R. Grimshaw, ed., Kluwer Academic Publishers, Dordrecht, The Netherlands, 61-88, 2001.
Rottman, J. W. and Linden,P. F.: Gravity currents, Chapter 4 in Environmental Stratified Flows, R. Grimshaw, ed., Kluwer Academic Publishers, Dordrecht, The Netherlands, 89-117, 2001.

Schott, F., Visbeck, M., and Fischer, J.: Observations of vertical currents and convection in the central Greenland sea during the winter of 1988-1989, J. Geophys. Res., 98, 14401-14421, 1993.

Simpson, J. E.: Gravity Currents in the Environment and the Laboratory. Second Edition, Cambridge University Press, 244pp, 1997.

Strauch, R. G., Weber, B. L., Frisch, A. S., Little, C. G.,. Merritt, D. A, Moran, K. P., and Welsh, D. C.: The precision and relative accuracy of profiler wind measurements, J. Atmos. Oceanic Technol., 4, 563-571, 1987.

Stull, R. B.: An Introduction to Boundary Layer Meteorology. Kluwer Academic Publishers, Hingham MA, 666 pp., 1988.

Van Zandt, T. E.: A brief history of the development of windprofiling or MST radars, Ann. Geophys., 18, 740-749, 2000.

Weber, B. L., Wuertz, D. B., Law, D. C., Frisch, A. S., and Brown, J. M.: Effects of small-scale vertical motion on radar measurements of wind and temperature profiles, J. Atmos. Oceanic Technol., 9, 193-209, 1992. 